\title{
Construction of Public Security Warning Mechanism Based on Internet Public Opinion Analysis
}

\author{
XiaoSong Tang \\ Liaoning Police College \\ Liaoning Dalian 116036, China
}

\begin{abstract}
Public security is one of the most important needs of human social life, so thepublic security early warning mechanism based on network public opinions is trying toexplore the public security early warning in the network technology development. With the progress of Internet technology, the network of publicopinion has an important value in the provision of public security early warninginformation.
\end{abstract}

KeywordsPublic Security; Warning Mechanism; Internet Public Opinion

\section{INTRODUCTION}

\section{A. Public Safety Warning Mechanism}

In recent years, public safety warning is the most important part of public management research, and is also social security mechanism that public management body is actively building. Since modern society is a society full of risks, the outbreak and spread of social risk events would have serious implications for public safety, leading social disruption and loss. Therefore, in the course of public administration, how to get ahead of the outbreak affecting public safety information or potential hazards, so as to make the necessary preparations, is a very important issue.

As a mechanism to predict whether public safety is threatened, public safety warningmechanism has great value for public administration. Public safety warning based onfull grasp of the information of social risk events, is the predict behavior of social risk events may have a significant impact on public safety risk. First, warning is to foresee possible public safety incidents; second, public Safety warning mechanism can be used to monitor the development process of public safety incidents; third, public safety warning can prevent the occurrence of public safety event.

\section{B. Internet Public Opinion}

Compared with traditional media, public opinions on Internet media have a diversitycharacteristic. First, because of the openness of the Internet participation, every social people can express their views, making the Internet public opinion showing a wide range of characteristics. Second, Internet public opinion has body hidden features: Internet participants express their views with their virtual identity, concealing their identity information. Third, Internet public opinion has fuzziness features: hot event reports can be reproduced on Internet, which makes the information sources become blurred, and sometimeslacks the corresponding check mechanism for some information. Fourth, Internet public opinion has directional views features: when a certain public opinion appears, related mainstream public opinion will have a clear point. Last, Internet public opinion has emotional features: since the Internet participants involved in the network with a hidden identity, free from real-world pressure, it makes the network public opinion participants to express their views often with emotional characteristics.In recent years, some hot Internet public opinion event, we can find the network public opinion gradually moves towards public trial from comments. Due to the lack of real information about the incident, participants applyInternet violence on the parties. Suchnegative pressure will not only cause pressure on the parties, but also cause pressure on public management authority governance activities.

\section{FUNCTIONAL ROLES OF INTERNET PUBLIC OPINION ANALYSIS ON PUBLIC SAFETY WARNING}

Internet public opinion reflects the attitude of the users of certain events or specific objects in social reality, so Internet public opinion and social reality are closely linked, and the groups attitudes and psychological reflected in Internet public opinion are the root causes of social reality. In certain circumstances, Internet public opinion will lead to social collective action. Therefore, when we guarantee social security and stability, we make use of Internet public opinion to carry out public safety warning. Functional roles of internet public opinion analysis on public safety warning are in the following aspects:

First, some hotspots public opinion prompts important social events. We should note that, some Internet public opinions might be have a negative impact on public safety, so these negative public opinions should enter the ranks of 
the network of early warning. Negative public opinion is more easily spread through the network and stimulate negative social emotions. Over-rising Internet public opinion may presage a collective social action.

Second, Internet public opinion may prompt certain social crisis. Speech and tendentious of participants is reflection of social psychology, which indicates the existence of objective social contradictions or conflicts. In the Internet space, because of the breadth of information dissemination, this negative attitude will be accepted by more people, and with no doubt that, it will influence social solidarity and the legality of the government administrative behavior, even evolving into a serious social crisis.

Third, potential of the Internet technology has made the role of Internet public opinion on public safety warning more and more important. In twenty years of Internet development, virtual existence has become a way of human existence. The tremendous change the Internet has brought to people's lives is undoubtedly reflection of the potential of Internet technology.

Fourth, Internet public opinion is also society member's response to the public safety incidents. Role of the network of public opinion is a polyhedron: on the one hand, Internet public opinion reflects a certain mindset of society members; on the other hand, as concerns about a particular event, Internet public opinionmay lead to socialcollective action, forming public safety incidents. In some ways, Internet public opinion is also society member's response to the public safety incidents. When public safety incidents occur, Internet public opinion rising shows how much the social members are concerned about it. In general, from outbreak of public safety incidents to public administration's attention, it requires an information transfer process, which means that government is not necessarily the information winners. If government regulatorsobtain such information in a timely manner through monitoring public opinion, they are able to carry out early treatment of such events; on the contrary, because of the nature of the work of government departments and public security program of early warning mechanism is not perfect, timely obtaining information of public safety incidents is difficult, so public opinion monitoring plays this role.

In the future, Internet is not only a place for people to communicate, but also place of life. The relationship between virtual world and real world will be closer. It means expansion of the world of human existence. Thus for the development trend of Internet technology, we should have sensitivity in Internet public opinion research.

\section{FUNCTIONAL ROLES OF INTERNET PUBLIC OPINION ANALYSIS ON PUBLIC SAFETY WARNING}

\section{A. Build Information Collection and Analysis Platform}

To implement public security early warning based on Internet public opinion, the first step is to obtain the information of Internet public opinion, so we need to build information collection and analysis platform. Internet public opinioninformation collection and analysis platform should meet the following requirements:

(1) First, the platform can complete comprehensive and accurate network information acquisition. Most of current Internet information collection platform lack of ability to distinguish the authenticity of the information, so in the practice of public opinion monitoring and analysis, the platform can continually improved according to the actual needs.

(2) Second, the platform can complete multi-dimensional real-time monitoring of network public opinion information. Internet contents are complex and diverse, and information is extremely large amount. The platform should be able to implementmulti-channel links, such as portal, forum, BBS, Blog, WeChat, etc.; do classification monitoring of public opinion information; information sources, information publishing time, attention trend, etc., can be visually manifested in the platform, so as to distinguish the attention of Internet public opinion.

(3) Third, the platform can automaticallydiscover Internet public opinion hotspot. Hot public opinion is also the principal object of attention of public opinion monitoring, which is generally wide-spread, high-concerned and highimpact public opinion, because it is more likely to cause a significant impact on the social collective action.

\section{B. Cultivate Specialized Internet Public Opinion Analyst}

Internet public opinion analysis platform is the hardware, while manual analysis is still the focus. Manual analysis requires professional network public opinion analyst, who need to grasp not only basic Internet knowledge, but also related technologies Internet public opinion analysis. First, from the perspective of the special nature of Internet public opinion, public opinion analyst should possess the skills of Internet information collection, identification, classification and information sensitivity; second, public opinion analyst need to master some of the analysis software and methods; third, public opinion analyst should be familiar with certain basic knowledge ofpolitical science, statistics, news media, public administration discipline. And in addition, Internet public opinion analyst should keep value neutrality in the work process, so that they maintain a certain degree of discrimination and analysis ability of public opinion analysis results of the study.

In the current, professional Internet public opinion analyst in our countrypublic administration is quite rare, while in some research institutes and national media organizations have reserved some relevant personnel, so in order to improve the operational capacity and level,public administration can cooperate with these institutions, to achieve a combination of business practice and theoretical research. 


\section{Develop Internet Public Opinion Analysis Methodology}

Internet public opinion analysis methodology plays an important role in public safety warning system. Due to the huge amount of information Internet public opinion, to filter out a lot of useful information and obtain reliable analytical conclusions from the public opinion information, requires reliable public opinion analysis methodology.

\section{CONCLUSIONS}

What is the bestmethodology? We should compare analysis conclusions and development process, that is, the best conclusion is the conclusion thatconsistent with the development process of the event. We summarize the methodology from the level of propagation and motivation.

(1) Propagation Level.

First, analysis of propagation body. Identity of propagation body has the vital significance to the production of communication content and communication strategy adjustment. By interpretation of identity of propagation body, we find out their relationship with the audience, which is of great use for early warning.

Second, analysis of propagation content variation. Variation of propagation content means deviation of information in the process of propagation. Analysis of propagation content variation is conducive to screening rumors and seditious words, and understanding derived features of public opinion.

Third, analysis of propagation content effect. Analysis of propagation content effect is mainly to investigate the reprinted amount, reviews amount of target public opinion in the process of propagation.

(2) Motivation Level.

First, analyst of Interest situations of netizens. Interest situations of netizens mainly include policy and product. If netizen's interest suffers damage, they would likely help spread some certain public opinion.

Second, analyst of group mental status. Conclusions: Generally, when the group consciousness appears, the spread of network public opinion has great appeal to the group. There, this analysis mainly investigates the relationship between motivation of Internet public opinion and social group mental status.

\section{REFERENCE}

[1] Savigny H. Public opinion, political communication and the internet[J]. Politics, 2002, 22(1): 1-8.

[2] Guan Q, Ye S, Yao G, et al. Research and design of internet public opinion analysis system[C]//Services Science, Management and Engineering, 2009. SSME'09. IITA International Conference on. IEEE, 2009: 173-177.

[3] Sink G. Public safety warning network: U.S. Patent Application 11/677,481[P]. 2007-2-21.

[4] Bing X. Construction of the Warning Mechanism of Library Crisis [J] Library and Information, 2007, 2: 010.

[5] Zhou Y, Moy P. Parsing framing processes: The interplay between online public opinion and media coverage $[\mathrm{J}]$. Journal of Communication, 2007, 57(1): 79-98.

[6] XIE H, CHEN Z. Internet Information and the Pattern of Public Opinion Analysis in Depth [J]. Journal of China Youth University for Political Sciences, 2006, 3: 019. 